\title{
Mentors and manipulation
}

\section{How Nobel assistance helped a young researcher test a crazy idea.}

\section{G. J. V. Nossal}

rank Macfarlane Burnet and Joshua Lederberg, Nobel laureates of 1960 and 1958, are each giants: Burnet is the grand old man of Australian virology and immunology; Lederberg is the brilliant founder of the new discipline of bacterial genetics. During three heady months in 1957, I was the meat in their sandwich, and had the good fortune of instigating a turning point in the exciting problem of how cells make antibodies.

Mammals can make antibodies to virtually anything, including synthetic chemicals. How can the cells of the immune system, the lymphocytes, fabricate such diversity? Paul Ehrlich was the first to offer an answer in 1900 with his 'side-chain' theory. He imagined stereochemical configurations on antibodies that were complementary to corresponding configurations on foreign agents (antigens). He postulated that antibodies existed as 'side chains' on the surface of cells. When an antigen came along, it united with the appropriate side chains, which the cell then overproduced and - hey presto! - you have antibodies.

Kari Landsteiner doubted this, because tiny changes in a synthetic antigen altered the specificity of antibodies. Given the number of possible chemical antigens, it beggared belief that there could be such a variety of pre-existent side chains. Ehrlich's views gave way to the 'direct template' theory, which suggested that antibodies moulded themselves directly against the antigen concerned. Niels Jerne challenged this 'instructionist' view by renewing the suggestion that antibodies were preformed, arguing that even if there were as many as $10^{11}$ different natural antibodies, there could still be a million of each type in a millilitre of serum. All the antigen had to do was to find the 'right' antibody and somehow catalyse its mass production. David Talmage was the first to suggest that Jerne's theory might work if the relevant antibodies were receptors on lymphocytes - and so the argument went back to Ehrlich! Burnet had independently come to the same conclusion and fleshed out what he termed the 'clonal selection' theory. If there were some random generator of diversity among antibody genes, switched on during the development of lymphocytes, each cell might end up with just one kind of antibody on its surface. When an antigen entered the body, it would find the right lymphocyte and stimulate it to divide and mass-produce antibody. The lymphocyte population could be seen as a repertoire of specificities.

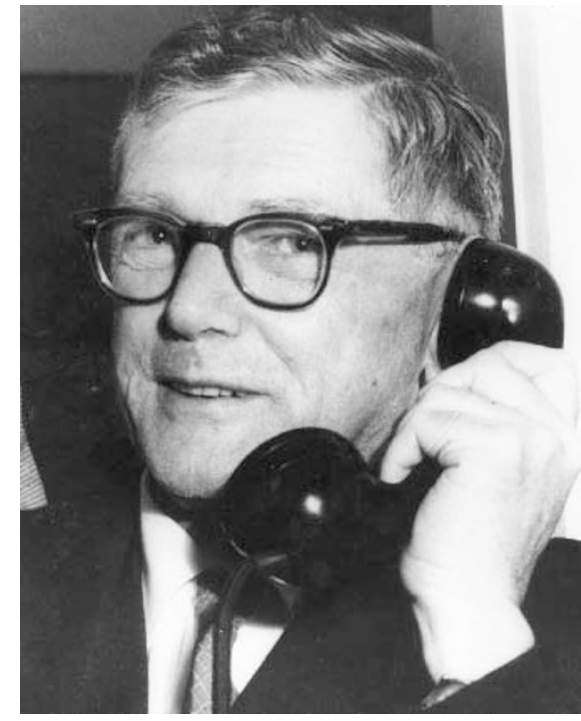

Ideas in immunology: Frank Macfarlane Burnet.

I was a naive research fellow joining Burnet's laboratory fresh out of medical school, and was asked what I thought. Frankly, it all seemed a bit crazy. Not having the courage to say that, I ventured to point out a way of disproving clonal selection. If a single cell from an animal that was immunized simultaneously with two antigens could produce both antibodies, the theory was wrong. Moreover, I knew that Lederberg - soon expected to arrive at our laboratory as a Fulbright visiting professor — was expert in micromanipulation. Perhaps he would help me to get single lymphocytes into microdroplets for short-term tissue culture.

When Lederberg arrived, he was deeply fascinated by Burnet's theory, preferring selective to instructive processes. We started our brief collaboration and chose immobilization of motile bacteria by anti-flagellar antibody as our assay. We immunized rats with killed Salmonella typhi and Salmonella adelaide.

Our only microscope was an old-fashioned Bausch and Lomb, with vertical rather than inclined eye-pieces - a good way of getting a crick in the neck. To see swimming bacteria we needed dark-field microscopy but, alas, we had no dark-field condenser. Undaunted, I simply removed the condenser and replaced it with a large Australian penny placed in such a way that an arc of light fell on to the specimen micromanipulation chamber, resulting in a fair imitation of dark-field illumination. We borrowed an ancient micromanipulator from the University of Melbourne across the road, and away we went.

Lymph nodes from immunized rats were teased into a suspension of single cells, then microdroplets that were hanging from a coverslip and surrounded by mineral oil were incubated for four hours. After this, 5-10 motile bacteria, first from one strain, then from the other, were micropipetted into each droplet. Regretfully, Lederberg had to leave before the first results trickled in, but our Nature paper (181, 1419-1420, 1958), although technically far from perfect, supported the one cell : one antibody concept.

Over four years, two in collaboration with Olavi Mäkelä, we studied 3,628 active single cells. Only two actually secreted antibody reactive with two bacterial strains, presumably representing cross-reactivities not detectable at the whole-serum level or, alternatively, binucleate cells, which are not all that uncommon among antibody-forming cells.

On his return to Finland, Mäkelä showed that each cell had its own unique fingerprint of antibody specificity, a great prelude to the qualities we now know monoclonal antibodies to possess, and in exact agreement with clonal selection. In a further collaboration with Gordon Ada, we made autoradiographs of single, antibody-forming cells from rats that had received a very highly radioactive antigen. In a situation where one silver grain above background would have represented four molecules of antigen, the mean grain count over 216 single antibodyproducing cells was -0.4 . There simply was no antigen in them, so the direct template theory was dead.

But what was really needed for formal proof was to take single cells from unimmunized animals that had been fractionated to react with a specific antigen; then clone them in vitro and demonstrate that the antibody formed had the same specificity as the receptors on the original B cell. When Beverley Pike and I finally did this in 1976, the results occasioned little comment because, essentially, clonal selection had won the day. The generator of diversity of antibodies turned out to be a unique somatic mini-gene shuffling and reassembly process.

For six years after the turning point, my colleagues and I had the study of antibody formation by single cells to ourselves, as the micromanipulation techniques were far too tedious for most investigators. Then a much simpler plaque technique came along and everybody could play the game. By that time, we had discovered a fascinating new cell, the follicular dendritic cell, that held the key to immunological memory. But that turning point will have to wait for another day. G. J. V. Nossal is in the Department of Pathology, the University of Melbourne, Victoria 3010, Australia. 